Violência, pp. 40-46. In Câmara dos Deputados (Coordenação de Publicações). Violência urbana e segurança pública. Câmara dos Deputados, Brasília.

Zaluar A 2002. Diagnóstico da violência urbana no Brasil, pp. 18-19. In Câmara dos Deputados (Coordenação de Publicações). Violência urbana e segurança pública. Câmara dos Deputados, Brasília.

\section{Homens e saúde: diversos sentidos em campo}

Men and health: several senses in field

\section{Pedro Nascimento 5}

Para mim é uma grande satisfação a oportunidade de participar deste debate que considero tão importante. Além da pertinência do tema que já valeria a empreitada, o artigo "Homens e saúde na pauta da Saúde Coletiva” consegue mapear diversas dimensões de um mesmo campo. Se por um lado essa amplitude deixa o debatedor com vontade de referir várias questões ao mesmo tempo - o que é aqui impossível; por outro, oferece ao leitor uma oportunidade ímpar de reflexão pelo que parabenizo os autores.

Também gostaria de situar minha fala: o lugar onde surgem meus questionamentos cruza a experiência de um antropólogo "iniciado" em bares junto de sujeitos que, reunidos, aprendiam a ser homens (Nascimento, 1995), com a experiência de uma pessoa que participa dessa discussão propondo um espaço para a reflexão sobre os homens nos campos aqui discutidos. Não se trata de reinstalar uma pouco produtiva oposição entre produção de conhecimento e ativismo, mas dizer dos dilemas próprios de um campo em construção (Medrado et al., 2000). A apresentação desses dilemas, a propósito, é o maior mérito deste artigo. São alguns deles, que particularmente me chamam a atenção, de que estarei tratando.

Uma primeira questão que destaco é que o artigo aponta para a necessidade de refletirmos o que estamos dizendo quando falamos gênero e estimula a busca da superação da reificação no feminino. Se parece que há acordo quando a referência é ao caráter histórico e cultural do

\footnotetext{
${ }^{5}$ Instituto Papai, Recife PE. pedro@papai.org.br
}

gênero, muitas vezes parece haver ainda pouca clareza quando se afirma que é a mesma sociedade que orienta a construção de elaborações consideradas masculinas e femininas. Se é igualmente inegável que sua característica básica é a assimetria de gênero, o que quero chamar a atenção aqui é que a forma como sujeitos vivenciam essa dimensão em suas vidas é constituinte tanto de mulheres quanto de homens.

É ainda desse campo de discussão uma outra questão trazida pelos autores que diz respeito à lógica dos benefícios indiretos para as mulheres da participação dos homens no campo saúde, sexualidade e reprodução. O caminho a ser percorrido para se compreender o que significa afinal falar-se em homens como sujeitos de direitos. Como pensar em direitos em relação a quem não só sempre usufruiu dos mesmos, como ainda impediu que outros - outras, as mulheres - assim se insurgissem? Caricaturas à parte, há um longo caminho para que consigamos dar o lugar devido ao fato de tratarmos dos homens, por um lado, como uma categoria genérica e universal e, por outro, falar dos sujeitos concretos do dia a dia.

Os autores enfrentam esse dilema o tempo todo. Referências a expressões como "masculinidade hegemônica", "padrões hegemônicos" etc., as quais são fundamentais para possibilitar mesmo a caracterização, trazem os riscos das generalizações e por isso os autores recomendam que não se pode desconsiderar a existência dos diferentes estilos de masculinidade, pois na vida cotidiana devemos levar em conta a posição concreta e particular dos sujeitos em cada grupo de referência. Isto, contudo, não é uma tarefa fácil, pois a referência ao modelo traz sempre a "tentação" da facilidade de achar que já conhecemos o que se nos apresenta antes mesmo de nos darmos ao trabalho de investigar a fundo suas múltiplas dimensões. Como não nos deslumbrarmos com a certeza tantas vezes repetida em diferentes espaços de que "os homens são assim"? Neste sentido, valorizar e dar visibilidade à diversidade dos sujeitos tem, por um lado, o apelo da pertinência metodológica e, por outro, a força da busca da superação dos estereótipos (Nascimento, 1999).

Uma outra questão tem a ver com a discussão sobre masculinidade e trabalho. A centralidade do trabalho na vida dos homens e na negociação de suas identidades; os desafios postos quando não são capazes de atualizar a prerrogativa de provimento financeiro do lar e mesmo a inconstância do trabalho precisam ser le- 
vadas em conta. No entanto, acredito que sua relação com os comportamentos associados ao uso abusivo de álcool precisam ser tratados com cautela. Para entendermos as implicações e conseqüências dessa relação, será preciso associálas a uma compreensão mais geral sobre os significados da bebida e do "beber junto" para os homens e sua socialização para que o caminho desemprego-alcoolismo não obscureça outras questões envolvidas na questão homens e bebida. Muito embora o alcoolismo seja também um grave problema de saúde pública, tive grandes dificuldades para caracterizar em minhas investigações etnográficas homens desempregados e dependentes financeiramente de mulheres (mães, esposas, irmãs) que eram todos eles dependentes de álcool (Nascimento, 2000).

Inicialmente, entendia aquele quadro como demonstrando que aqueles homens, estando impossibilitados de cumprirem com a prerrogativa do trabalho e do provimento do lar, não conseguiam redefinir o ambiente doméstico, nem criar novos sentidos para as suas vidas. Sendo assim, o universo da bebida apresentavase como a única possibilidade. Uma espécie de alternativa perversa diante da impossibilidade de redimensionamento do espaço doméstico, eminentemente feminino. Esta visão precisou dar lugar a uma busca dos possíveis sentidos da condição daqueles homens para que, inclusive, permitisse não constituir uma tendência à sua vitimização.

O dilema de perceber esses homens como dependentes químicos e ao mesmo tempo viabilizar uma interpretação, que não os considerasse apenas a partir da posição de "doentes", pôde ser enfrentado na medida em que outros elementos de suas trajetórias puderam ser trazidos à tona, de modo que o álcool, mesmo sendo uma dimensão fundamental, foi considerada junto com outras, como as diferentes relações mantidas e as redes de solidariedade construídas, os discursos sobre a bebida e sobre a falta de trabalho, a alternância de momentos de bebida com momentos de abstinência, a manipulação da identidade de doentes etc. Elementos esses que permitem não vermos esses homens apenas como "alcoolistas", nem as relações em que estão inseridos como marcadas exclusivamente pela compaixão das pessoas que deles cuidam.

Uma última questão que gostaria de apresentar está associada à discussão de que os homens não são ensinados a cuidar nem de si nem do outro. Para refletirmos sobre o que estamos falando sobre "participação masculina” ou "envolvimento masculino", faz-se importante analisar também como os serviços de saúde de uma forma geral e no campo da saúde sexual e reprodutiva, em particular, estão estruturados refletindo a organização com base no gênero.

O enfoque marcadamente materno-infantil da atenção básica em saúde faz com que serviços, que muitas vezes são deficitários para identificar as especificidades das mulheres, sequer reconheçam os homens como sujeitos de sua atenção. Ao fazer isto, cristaliza oposições construídas socialmente como se fossem dados da natureza: desestimula os homens a procurarem os serviços de saúde e enxerga as mulheres como essencialmente cuidadoras e as únicas responsáveis pela esfera da saúde.

Não se trata de negar uma relação diferenciada de homens e mulheres nesse aspecto, mas, uma vez percebida essa diferenciação, de nada adiantará apenas insistir na queixa: os homens não cuidam, os homens não participam... Esta perspectiva, a princípio, traz dois resultados que pouco ajudam na superação dessa dificuldade: 1) acaba por transformar, pela ênfase, um dado cultural e historicamente construído, num argumento de base essencial, como se existisse algo dado nos homens que os fariam descomprometidos, desligados, gerando o discurso de que os homens não querem, ao invés de investigar e agir nos elementos que levam os homens a "não quererem" ou não "participarem"; 2) uma vez configurada essa compreensão, passase a tratar como se qualquer ação junto dos homens exigisse um esforço sobre-humano para se identificar a fórmula para "atingir" esses mesmos homens, sem que antes tenha se refletido suficientemente sobre os "lugares" e os "não-lugares" construídos cotidianamente na relação com essa população.

Reconhecer a existência desses sujeitos nessa área não significa reivindicar aos homens um lugar de destaque, tampouco vitimizá-los. A percepção é de que a participação dos homens passa pela superação de imagens e perspectivas individualizantes e culpabilizantes, dando lugar a espaços de atenção, reconhecimento de demandas, abertura para identificar especificidades. Isto pressupõe ouvir os homens e convidálos à participação. Porém é importante que esta escuta e este convite aconteçam também por poderem significar algo importante para estes sujeitos e não apenas porque estes tenham de ser “responsáveis” (Arilha, 2000). 


\section{Referências bibliográficas}

Arilha M 2000. Homens jovens, gênero e masculinidades. Perspectivas em Saúde e Direitos Reprodutivos 3:22-25.

Medrado B, Lyra J, Galvão K \& Nascimento P 2000. Homens, por que? Uma leitura da masculinidade a partir de um enfoque de gênero. Perspectivas em Saúde e Direitos Reprodutivos 3:12-16.

Nascimento P 1995. Mulher é o cão: a construção da identidade masculina em bar da feira central de Campina Grande/PB. Monografia de graduação.UFPB, Campina Grande.

Nascimento P 1999. Ser homem ou nada: diversidade de experiências e estratégias de atualização da masculinidade hegemônica em Camaragibe/PE. Dissertação de mestrado. UFPE, Recife.

Nascimento P 2000. Homens pobres, masculinidades à margem. A construção social da masculinidade no município de Camaragibe/PE. Relatório de pesquisa. PRODIR III - Fundação Carlos Chagas-Fundação MacArthur, São Paulo.

\section{Comentários diagonais sobre a emergência dos homens na pauta da Saúde Coletiva \\ Diagonal comments about the men emergency in the Public Health targets}

\section{Sérgio Carrara 6}

Como ressaltam Schraiber, Gomes e Couto, temos assistido nos últimos anos, na área da Saúde Coletiva e na das Ciências Sociais aplicadas à saúde, a uma crescente preocupação em situar no centro da análise os homens e a(s) masculinidade(s). Colocando-me em uma perspectiva complementar àquela adotada pelos autores, farei aqui alguns comentários referentes à história e aos possíveis significados da emergência dos homens - considerados categoria de gênero e não mais representantes universais da espécie humana - como objetos de pesquisa e intervenção científica.

Tenho como pressupostos que os nossos objetos de reflexão não se oferecem passivamente à observação, como se tivessem estado sempre lá, na "realidade social", à espera de serem "descobertos" e que tal "descoberta" tem sempre uma dimensão política. E talvez seja justamente

\footnotetext{
6 IMS-Uerj.carrara@uerj.br
}

a falta de clareza quanto às conseqüências políticas do estudo da(s) masculinidade(s) que ainda hoje faz com que os homens sejam abordados, como corretamente apontam os autores, de uma maneira "instrumental", ou seja, mais como fonte de agravos à saúde dos outros do que foco central do debate. Assim, ao estudarem os homens e a masculinidade, muitos ainda devem se perguntar, se não estariam "desperdiçando" recursos intelectuais, aumentando a visibilidade e o prestígio social de quem já os possui em excesso.

É claro que um tal dilema supõe a adesão à idéia de que as conseqüências políticas da transformação de determinado grupo ou categoria social em objeto de reflexão científica operariam sempre no sentido de seu empowerment social. Bem sabemos, entretanto, que há outras versões muito mais críticas, pessimistas ou antiiluministas sobre as conseqüências políticas do trabalho científico. Muitos acham, e penso aqui obviamente em Foucault, que o empreendimento científico geralmente é ele mesmo parte de processos mais amplos de dominação social e de sujeição política. Deveríamos então compreender a emergência dos estudos sobre masculinidade como espécie de "sintoma" de um processo de desarticulação do poder masculino? Não me parece absurdo afirmar, ao menos como hipóteses a serem consideradas, que, nos últimos dois séculos, assistimos não somente a uma lenta e progressiva corrosão do poder masculino, mas também que a tal corrosão corresponde o correlativo aumento do poder do Estado e do mercado.

Comecemos pelo mercado, no qual se incluem os próprios serviços voltados à manutenção e promoção da saúde (física ou mental), os produtos da indústria farmacêutica etc. Nesse âmbito, estamos assistindo a uma mudança sem precedentes quanto à sofisticação do antigo mercado produtor de serviços e bens que, voltados para os homens, procuravam expressar sua masculinidade. De fato, algo parece estar acontecendo no plano daquilo que Luc Boltanski chamava de cultura somática, fazendo com que homens de diferentes camadas sociais passem a manter com seus corpos um tipo de atitude antes considerada mais apropriada às mulheres. Mais reflexiva e mais atenta ao próprio corpo, tal atitude propicia e incentiva o consumo de um sem-número de serviços profissionais e produtos que prometem manter os corpos nas convenções ideais da cultura de massa dessa nossa passagem de século: saudáveis, sen- 